\title{
COMPARISON OF DENTAL TREATMENT PERFORMED UNDER GENERAL ANESTHESIA BETWEEN HEALTHY CHILDREN AND CHILDREN WITH SPECIAL NEEDS AT A TEACHING HOSPITAL IN EGYPT
}

\author{
Adel Abdel Aziem Elbardissy*
}

\begin{abstract}
BACKGROUND: The evaluation of dental treatment under general anesthesia (GA) in healthy children and children with special health care needs (SHCN) should take into consideration; firstly, the different dental treatment needs according to the disability condition (scope of disability) and secondly, the limitation of the treatment.
\end{abstract}

Aim of the study: This retrospective study aims at comparing the different dental treatment modalities performed under general anesthesia for healthy children, on one side, and those with special health needs, on the other. The Study was carried out at Unit for Dental Treatment of Healthy Children and Children with Special Needs, Faculty of Dentistry’ Teaching Hospital, Cairo University, in 2017 and 2018.

Method: This retrospective study was approved by the Research Ethics Committee, Faculty of Dentistry, Cairo University. Data was retrieved from the files of the pediatric patients, aged from 1 to 18 years old, who received dental treatment under GA, between January 2017 to December 2018, at this Unit. Patients with special needs, with either mental or physical disability, were assigned as Group A, while the healthy patients were assigned as Group B. The two Groups were compared for: the treatment modalities of operative restorations, pulp therapy, anterior and posterior crowns, fissure sealants, dental prophylaxis, and extractions of teeth. The number of repeated admissions for dental treatment under GA was also included in the Study.

Results: The total number of children who had dental treatment under GA in the years 2017 and 2018 was 2276 . Number of children with SHCN was 553 (24.3\%), while the number of healthy children was 1723 (75.7\%). Group A showed significantly higher mean age (7.04) than Group B (4.27), (P-value $<0.001)$. Group A showed a higher percentage of previous admissions for dental treatment under GA $(13.4 \%)$, than group B $(0.6 \%)$ (P-value $<0.001)$. The most frequent disability was cerebral palsy $(41.2 \%)$, followed by autism $(17.7 \%)$, then mental retardation $(15.2 \%)$. For primary dentition, Group A showed significantly higher prevalence of extractions for molars and incisors than Group B (P-value $<0.001$, effect size $=0.159$ and P-value $<0.001$, effect size $=0.150$,

\footnotetext{
* Associate Professor, Pediatric Dentistry, Faculty of Dentistry, Cairo University, Egypt.
} 
respectively), and higher prevalence of glass ionomer (GI) fillings for molars than Group B. Group A showed significantly lower prevalence of: composite fillings, GI fillings for incisors, pulpotomies, pulpectomies, and crowns. There was no statistically significant difference in amalgam filling treatments and fissure sealant applications between the two Groups. For permanent dentition, Group A showed significantly higher prevalence of amalgam fillings, composite fillings and crowns for molars than Group B. In addition, Group A showed significantly higher prevalence of dental prophylaxis than Group B.

Conclusions: The use of radical treatment as extraction of extensive decayed teeth in children with SHCN is observed in this Study. The use of crowns to protect the teeth even without pulp therapy is demonstrable in the treatment pattern revealed in this Study. A special attention should be directed toward preventive procedures such as dental prophylaxis, fissure sealants and topical fluoride application. Education of parents/caregivers is needed to implement and supervise the proper oral hygiene measures for the children with SHCN.

\section{INTRODUCTION}

The implemented pain-relief approach during treatment includes: behavioral management, local anesthesia, conscious sedation, and GA. Dental treatment under GA is more common for uncooperative patients with extensive dental problems ${ }^{1}$.

Behavior problems and inability to cooperate in children with multiple decayed teeth are the main reasons for pursuing treatment under $\mathrm{GA}^{2,3}$. Studies have shown that dental treatment performed under GA has achieved better moisture control and convenient restorative procedures, than under local anesthesia ${ }^{4,5,6}$.

The American Academy of Pediatric Dentistry defines Special Health Care Needs (SHCN) as “... any physical, developmental, mental, sensory, behavioral, cognitive, or emotional impairment or limiting condition that requires medical management, health care intervention, and/or use of specialized services or programs" 7 .

Typically, children with special health care needs are difficult to manage for a regular dental treatment in a conventional dental setting. The best approach for children under this category is to provide dental treatment under $\mathrm{GA}^{8}$.

Patients with medically handicapping conditions who benefit from GA include those with intellectual disability; such as autistic disorder ${ }^{9}$, cerebral palsy and mentally-retarded patients ${ }^{10}$.

Dental procedures under GA include different restorations, stainless steel crowns, pulp therapy (both for primary and permanent dentition), extractions, minor oral surgery, fissure sealants, prophylaxis, and fluoride treatments ${ }^{11}$.

Several literatures have studied dental treatment modalities under GA for children ${ }^{12-19}$. Most of these studies reported a higher percentage of extractions in children with SHCN than in healthy children ${ }^{12}$, ${ }^{14-19}$. Noticeably, some of these studies noted less frequency of pulp therapy and stainless steel crowns in children with $\mathrm{SHCN}^{12,16,17}$. However other studies reported a higher restorative treatment among the children with SHCN than in healthy children ${ }^{14,15}$.

Few researches compared dental treatment performed under GA between healthy children and children with SHCN in the Arab countries in general, and in Egypt in particular ${ }^{12}$. This study aims at comparing the different dental treatment modalities performed under GA for healthy children and children with SHCN, at the Hospital of the Faculty of Dentistry, Cairo University, Egypt, in the years 2017 and 2018, inclusive. 


\section{MATERIALS AND METHODS}

Unit for Dental Treatment of Healthy Children and Children with Special Needs, Faculty of Dentistry' Teaching Hospital, Cairo University, Egypt was established in year 2003. The operating theater is equipped with three dental units and three devices for general anesthesia (Fig.1).

The Unit, at the time of this Study, has thirteen qualified pediatric dentist, of various calibers and roles, e.g. lecturers, associate professors and professors. All were involved in the treatment of the children under GA. The Unit operates from Saturday to Thursday, with Saturday been allocated for the treatment of the children with SHCN.

All patients referred for treatment under GA have received a proper examination by a pediatric dental consultant. Patients with medical problems receive pre-anesthetic assessment at the Pediatric Clinics, each according to his/her medical conditions. A preprocedure blood test is performed to reveal complete blood count (CBC), bleeding time (BT), clotting time (CT), Hepatitis B surface antigen (HBs AG), and hepatitis $\mathrm{C}$ antibodies ( $\mathrm{HCV} \mathrm{Ab}$ ). Parents were informed of the procedure and proposed treatment plan. Then the child's name is placed on the waiting list. children might wait two to three weeks before their turn for the GA, depending on the length of the waiting list. On the day of the procedure, a written consent is obtained prior the operation. The patient is then transferred to the operating reception area to be re-examined by an anesthetist. After anesthetizing the child, a full examination is performed by the operating pediatric dentist, and the final treatment plane is discussed with the parents. Upon the conclusion of the procedure, the child gets awaken, and is sent to the recovery room for post-operative monitoring, before being fully discharged from the recovery room. Within 2 weeks, all patients are instructed to re-visit the pediatric dental clinic, in order to be re-seen and assessed by the operating dentist.
The Research Ethics Committee of Faculty of Dentistry Cairo University approved this Study. Data of the different dental treatment modalities performed to the children were retrieved from the patients' files. The Study covered all patients treated under GA in years 2017 and 2018.

The variables recorded for comparison and analysis in this Study were: gender, age, previous number of admissions for dental treatment under GA, type of disability for children with SHCN, types of preventive, restorative or surgical treatments done for both primary and permanent dentitions (Fig. 2, 3, 4). Patients' data were divided into two groups: Group A: Patients with SHCN, (who had at least one type of mental or physical disability), and Group B: patients who are healthy.

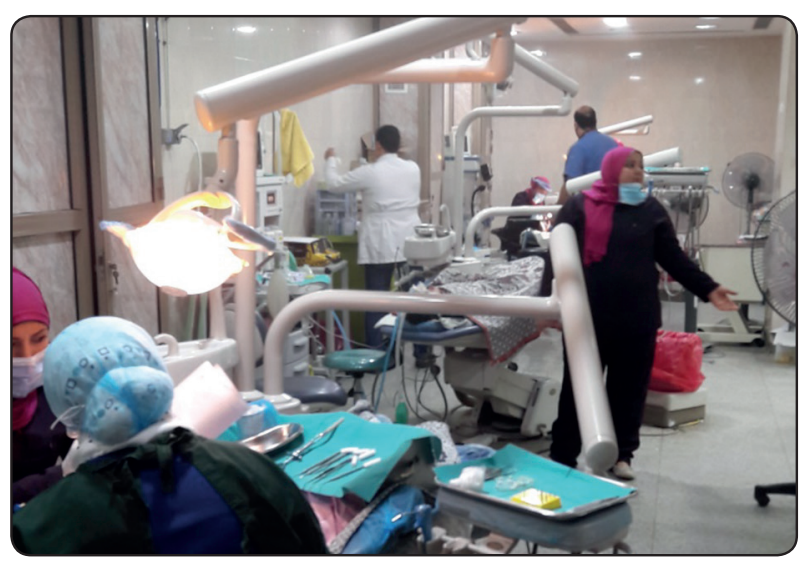

Fig. (1) Dental Theater for dental treatment under GA.

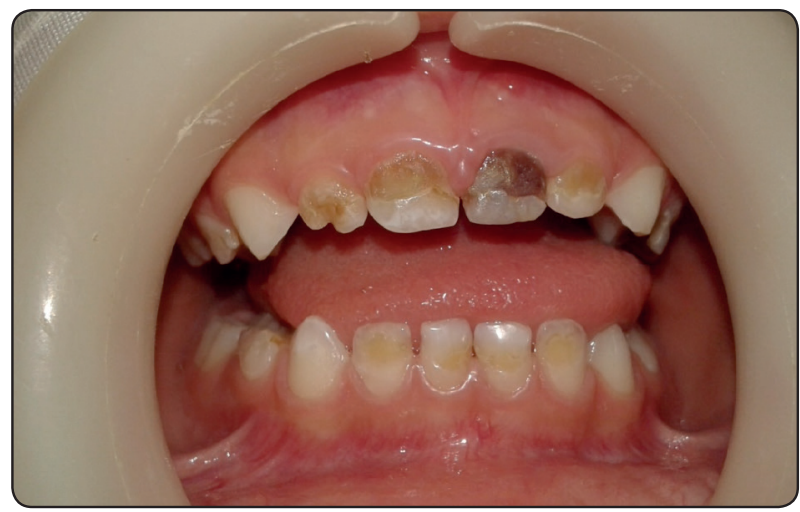

Fig. (2) A Patient admitted for treatment of early childhood caries under GA. 


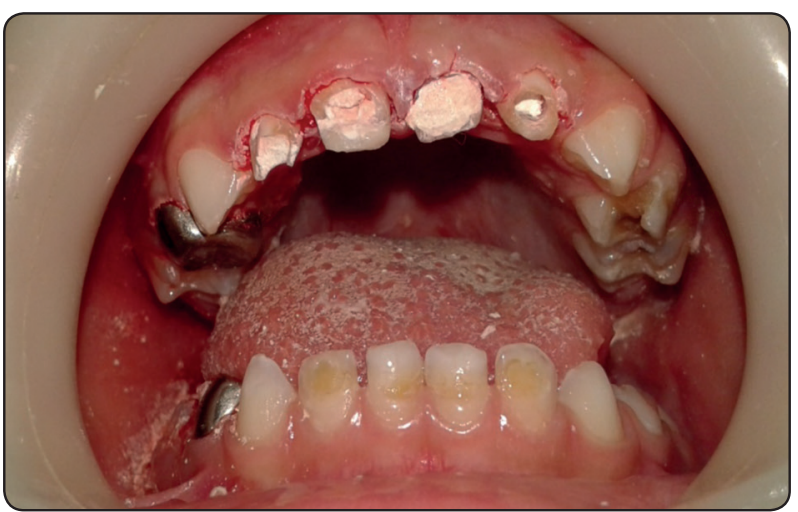

Fig. (3) Pulpectomy for the primary incisors, accessing the pulp fromlabial side,tomaintain theremaining tooth structure.

\section{Statistical Analysis}

Qualitative data were presented as frequencies and percentages. Quantitative data were presented as mean and standard deviation values. Chi-square test and Fisher's Exact test were used for comparisons regarding qualitative data. Student's t-test was used to compare between mean age values in the two groups. The significance level was set at $\mathrm{P} \leq$ 0.05. Statistical analysis was performed with $\mathrm{IBM}^{\circledR}$ SPSS ${ }^{\circledR}$ Statistics Version 20 for Windows.

\section{RESULTS}

\section{Base line characteristics}

Group A showed significantly higher mean age than Group B, (P-value <0.001). There was no statistically significant difference in gender distributions between the two Groups (P-value $=0.487)$. Group A showed significantly higher percentage of previous admission to GA than group B (P-value <0.001) (table 1).

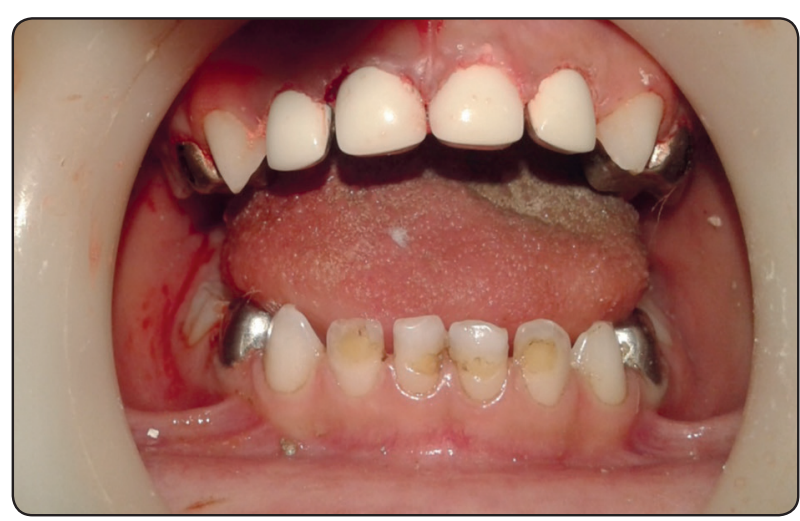

Fig. (4) Stainless steel crowns with facing for primary anterior teeth and stainless steel crowns for primary molars.

TABLE (1) Mean, standard deviation (SD), frequencies (n), percentages and results of Student's t-test and Chi-square test for comparisons of age, gender and number of previous dental treatment under GA in the two Groups:

\begin{tabular}{cccc}
\hline & $\begin{array}{c}\text { Group A } \\
(\mathrm{n}=553)\end{array}$ & $\begin{array}{c}\text { Group B } \\
(\mathrm{n}=1723)\end{array}$ & $P$-value \\
\hline Age (Years) & & & \\
Mean (SD) & $7.04(3.2)$ & $4.27(1.41)$ & $<0.001^{*}$ \\
\hline Gender [n (\%)] & & & \\
Boy & $312(56.4)$ & $943(54.7)$ & 0.487 \\
Girl & $241(43.6)$ & $780(45.3)$ & \\
\hline
\end{tabular}

Number of previous treatment under GA [n (\%)]

\begin{tabular}{|c|c|c|c|}
\hline $\begin{array}{l}\text { No previous } \\
\text { admission }\end{array}$ & 479 (86.6) & $1713(99.4)$ & $<0.001 *$ \\
\hline One time & $74(13.4)$ & $10(0.6)$ & \\
\hline
\end{tabular}

$*$ : Significant at $P \leq 0.05$ 


\section{Types of disability}

Various types of disabilities were documented. The most frequent disability was cerebral palsy $(41.2 \%)$ followed by autism $(17.7 \%)$, then mental retardation (15.2\%). Table (2) outlines the incidence of each type/disability.

TABLE (2) Descriptive statistics for different disabilities $(\mathrm{n}=553)$ :

\begin{tabular}{|l|c|c|}
\hline \multicolumn{1}{|c|}{ Disability } & $\mathrm{n}$ & $\%$ \\
\hline Cerebral palsy & 228 & 41.2 \\
\hline Autism & 98 & 17.7 \\
\hline Mental Retardation & 84 & 15.2 \\
\hline Down Syndrome & 48 & 8.7 \\
\hline Congenital Heart Disease & 19 & 3.4 \\
\hline Epilepsy & 14 & 2.5 \\
\hline ADHD & 8 & 1.4 \\
\hline Blood Disease & 8 & 1.4 \\
\hline Cleft Lip and Palate & 5 & 0.9 \\
\hline Blindness & 5 & 0.9 \\
\hline CGD & 4 & 0.7 \\
\hline Multiple Sclerosis & 4 & 0.7 \\
\hline Open Heart Surgery & 4 & 0.7 \\
\hline Bronchial Asthma & 3 & 0.5 \\
\hline Quadriplegia & 3 & 0.5 \\
\hline Spinal Muscular Atrophy & 3 & 0.5 \\
\hline Microcephaly & 3 & 0.5 \\
\hline Bone Marrow Failure & 2 & 0.4 \\
\hline Syndrome & 2 & 0.4 \\
\hline Hydrocephalus & 2 & 0.4 \\
\hline Kidney Operation & 2 & 0.4 \\
\hline Liver Transplant & 1 & 0.4 \\
\hline Wilson Disease & & 0.2 \\
\hline Lung Fibrosis & 2 \\
\hline Deafness & 2 \\
\hline
\end{tabular}

Primary Dentition Treatments (Table 3, Fig. 5):

Extractions: Group A showed significantly higher prevalence of extractions for molars and incisors than Group B (P-value <0.001, Effect size $=0.159$ and $\mathrm{P}$-value <0.001, Effect size $=0.150$, respectively).

Amalgam fillings: There was no statistically significant difference between amalgam filling treatments in the two Groups (P-value $=0.717$, Effect size $=0.008$ and $\mathrm{P}$-value $=0.170$, Effect size $=0.029$, respectively).

Composite fillings: Group (A) showed significantly lower prevalence of composite fillings for molars and incisors than Group B (P-value $<0.001$, Effect size $=0.138$ and P-value $<0.001$, Effect size $=0.143$, respectively).

GI fillings: Group A showed significantly higher prevalence of GI fillings for molars than Group B, $(\mathrm{P}$-value $<0.001$, Effect size $=0.083)$. Group A showed significantly lower prevalence of GI fillings for incisors than Group B, (P-value $=0.036$, Effect size $=0.044)$.

Pulpotomy: Group A showed significantly lower prevalence of pulpotomy for molars and incisors than Group B (P-value $<0.001$, Effect size $=0.233$ and $\mathrm{P}$-value $=0.008$, Effect size $=0.056$, respectively).

Pulpectomy: Group A showed significantly lower prevalence of pulpectomy for molars and incisors than Group B (P-value $<0.001$, Effect size $=0.076$ and $\mathrm{P}$-value <0.001, Effect size $=0.124$, respectively).

Stainless Steel/Zirconia crowns: Group A showed significantly lower prevalence of Stainless Steel/Zirconia crowns for molars and incisors than Group B (P-value <0.001, Effect size $=0.480$ and $\mathrm{P}$-value $<0.001$, Effect size $=0.297$, respectively).

Fissure sealant: There was no statistically significant difference between fissure sealant applications in the two Groups (P-value $=0.346$, Effect size $=0.029$ ). 
Permanent Dentition Treatments (Table 4, Fig 6):

Extractions: Group A showed significantly higher prevalence of extractions for molars and incisors than Group B (P-value $<0.001$, Effect size $=0.362$ and $\mathrm{P}$-value <0.001, Effect size $=0.174$, respectively).

Amalgam fillings: Group A showed significantly higher prevalence of amalgam fillings for molars than Group B (P-value <0.001, Effect size $=0.348)$. No amalgam fillings were introduced to permanent incisors in the two Groups.

Composite fillings: Group A showed significantly higher prevalence of composite fillings for molars and incisors than Group B (P-value $<0.001$, Effect size $=0.113$ and P-value $<0.001$, Effect size $=0.087$, respectively).

TABLE (3) Descriptive statistics and results of Chi-Square and Fisher's Exact Tests for comparison between primary dentition treatments in the two Groups:

\begin{tabular}{|c|c|c|c|c|c|c|c|}
\hline \multirow[b]{2}{*}{ Treatment } & & \multicolumn{2}{|c|}{ Group A $(\mathrm{n}=553)$} & \multicolumn{2}{|c|}{ Group B $(n=1723)$} & \multirow{2}{*}{$P$-value } & \multirow{2}{*}{ Effect size (v) } \\
\hline & & $\mathrm{n}$ & $\%$ & $\mathrm{n}$ & $\%$ & & \\
\hline \multirow{2}{*}{ Extractions } & Molars & 380 & 68.7 & 866 & 50.3 & $<0.001 *$ & 0.159 \\
\hline & Incisors & 240 & 43.4 & 469 & 27.2 & $<0.001 *$ & 0.150 \\
\hline \multirow{2}{*}{$\begin{array}{l}\text { Amalgam } \\
\text { fillings }\end{array}$} & Molars & 91 & 16.5 & 295 & 17.1 & 0.717 & 0.008 \\
\hline & Incisors & 13 & 2.4 & 61 & 3.5 & 0.170 & 0.029 \\
\hline \multirow{2}{*}{$\begin{array}{l}\text { Composite } \\
\text { fillings }\end{array}$} & Molars & 39 & 7.1 & 324 & 18.8 & $<0.001^{*}$ & 0.138 \\
\hline & Incisors & 27 & 4.9 & 281 & 16.3 & $<0.001 *$ & 0.143 \\
\hline \multirow{2}{*}{ GI fillings } & Molars & 5 & 0.9 & 0 & 0 & $<0.001 *$ & 0.083 \\
\hline & Incisors & 26 & 4.7 & 125 & 7.3 & $0.036^{*}$ & 0.044 \\
\hline \multirow{2}{*}{ Pulpotomy } & Molars & 169 & 30.6 & 994 & 57.7 & $<0.001^{*}$ & 0.233 \\
\hline & Incisors & 0 & 0 & 22 & 1.3 & $0.008 *$ & 0.056 \\
\hline \multirow{2}{*}{ Pulpectomy } & Molars & 15 & 2.7 & 119 & 6.9 & $<0.001^{*}$ & 0.076 \\
\hline & Incisors & 20 & 3.6 & 214 & 12.4 & $<0.001 *$ & 0.124 \\
\hline \multirow{2}{*}{$\begin{array}{l}\text { St. St./Zirconia } \\
\text { crowns }\end{array}$} & Molars & 270 & 48.8 & 1588 & 92.2 & $<0.001^{*}$ & 0.480 \\
\hline & Incisors & 51 & 9.2 & 724 & 42 & $<0.001^{*}$ & 0.297 \\
\hline Fissure sealants & & 0 & 0 & 6 & 0.3 & 0.346 & 0.029 \\
\hline
\end{tabular}

*: Significant at $P \leq 0.05$

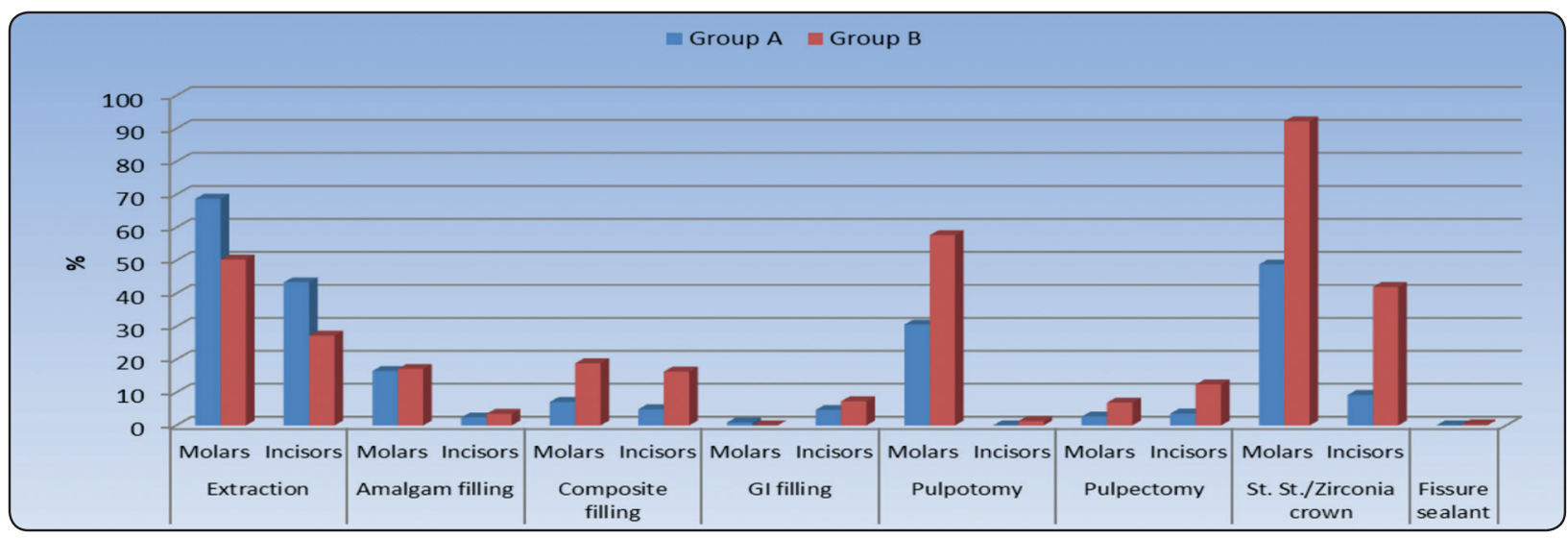

Fig. (5) Bar chart representing primary dentition treatments in the two groups 
GI fillings: There was no statistical significant difference between prevalence of GI fillings for molars in the two Groups (P-value $=0.059$, Effect size $=0.052$ ). No GI fillings were introduced to permanent incisors in the two Groups.

Pulpotomy: There was no statistical significant difference between prevalence of pulpotomy for molars and incisors in the two Groups (P-value
$=0.190$, Effect size $=0.031$ and P-value $=0.344$, Effect size $=0.027$, respectively).

Pulpectomy: There was no statistical significant difference between prevalence of pulpectomy for molars in the two Groups (P-value $=0.344$, Effect size $=0.027)$. No pulpectomies were introduced to permanent incisors in the two Groups.

TABLE (4) Descriptive statistics and results of Chi-square and Fisher's Exact Tests for comparison between permanent dentition treatments in the two Groups:

\begin{tabular}{|c|c|c|c|c|c|c|c|}
\hline \multirow{2}{*}{ Treatment } & & \multicolumn{2}{|c|}{$\begin{array}{l}\text { Group A } \\
(\mathrm{n}=553)\end{array}$} & \multicolumn{2}{|c|}{$\begin{array}{c}\text { Group B } \\
(\mathrm{n}=1723)\end{array}$} & \multirow[t]{2}{*}{$P$-value } & \multirow[t]{2}{*}{ Effect size $(v)$} \\
\hline & & $\mathrm{n}$ & $\%$ & $\mathrm{n}$ & $\%$ & & \\
\hline \multirow{2}{*}{ Extraction } & Molars & 103 & 18.6 & 8 & 0.5 & $<0.001 *$ & 0.362 \\
\hline & Incisors & 22 & 4 & 0 & 0 & $<0.001 *$ & 0.174 \\
\hline Amalgam filling & Molars & 113 & 20.4 & 22 & 1.3 & $<0.001 *$ & 0.348 \\
\hline \multirow{2}{*}{ Composite filling } & Molars & 19 & 3.4 & 9 & 0.5 & $<0.001 *$ & 0.113 \\
\hline & Incisors & 11 & 2 & 5 & 0.3 & $<0.001 *$ & 0.087 \\
\hline GI filling & Molars & 2 & 0.4 & 0 & 0 & 0.059 & 0.052 \\
\hline \multirow{2}{*}{ Pulpotomy } & Molars & 2 & 0.4 & 18 & 1 & 0.190 & 0.031 \\
\hline & Incisors & 0 & 0 & 5 & 0.3 & 0.344 & 0.027 \\
\hline Pulpectomy & Molars & 0 & 0 & 5 & 0.3 & 0.344 & 0.027 \\
\hline \multirow{2}{*}{$\begin{array}{l}\text { St. St./Zirconia } \\
\text { crown }\end{array}$} & Molars & 20 & 3.6 & 4 & 0.2 & $<0.001 *$ & 0.142 \\
\hline & Incisors & 0 & 0 & 4 & 0.2 & 0.578 & 0.024 \\
\hline Fissure sealant & & 1 & 0.2 & 0 & 0 & 0.243 & 0.037 \\
\hline Dental prophylaxis & & 9 & 1.6 & 12 & 0.7 & $0.046^{*}$ & 0.042 \\
\hline
\end{tabular}

*: Significant at $P \leq 0.05$

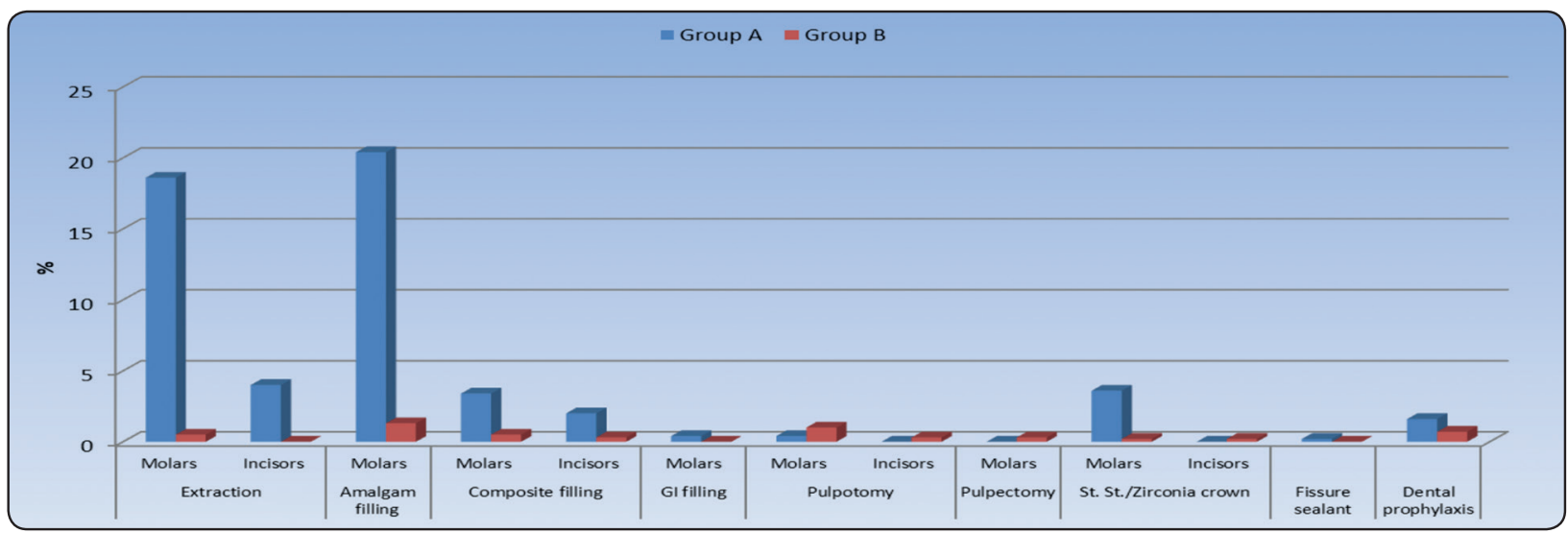

Fig. (6) Bar chart representing permanent dentition treatments in the two groups 
Stainless Steel crowns: Group A showed significantly higher prevalence of St. St. crowns for molars than Group B (P-value <0.001, Effect size $=0.142)$. There was no statistical significant difference between prevalence of Stainless Steel crowns for incisors in the two Groups (P-value = 0.578 , Effect size $=0.024$ )

Fissure sealants: There was no statistical significant difference between fissure sealant applications in the two Groups (P-value $=0.243$, Effect size $=0.037$ ).

Dental prophylaxis: Group A showed significantly higher prevalence of dental prophylaxis than Group B (P-value $=0.046$, Effect size $=0.042)$.

\section{DISCUSSION}

Unit for Treatment of Children and those with Special Health Care Needs, Faculty of Dentistry' Teaching Hospital, Cairo University, Egypt, is the only Unit across Egypt that offer dental treatment under GA, either free of charge or for nominal fee. Patients from various governorates around Egypt are entitled to be treated at this Unit. This explains the large number (n. 2276) of patients treated within the span of this retrospective study, in comparison with other studies ${ }^{13-17}$.

At the time of treatment, Group A showed significantly higher mean age than Group B. This is attributable to the fact that the need for dental treatment under GA in Group B is often associated with very young age where cooperation is not easily achievable. This result is in agreement with the results of Al-Ogayyel and Al-Haj ${ }^{12}$ and Lee et al ${ }^{16}$.

The Study affirms that there is no statistically significant difference in gender distributions between the two Groups; with males outnumbered females in both Groups. This was found in most of the studies comparing gender of children treated under GA ${ }^{20,21,22}$.

Children with SHCN showed more percentage of previous dental treatment under GA (13.4\%), than healthy children (0.6). This may be due to the difficulty of providing dental treatment for the children with SHCN in a conventional dental setting with advancing in age contrary to the normal children group. This result came in accordance to the results of Berkowitz et al ${ }^{23}$.

The most noted disability was cerebral palsy (41.2\%), followed by autism (17.7\%), then mental retardation $(15.2 \%)$. This indicates that intellectual disabilities are the main cause for the difficulty of managing dental treatment for those children in conventional dental settings. Other studies pointed out that either congenital heart diseases ${ }^{11}$, or respiratory disorders ${ }^{16}$, as being the main disability of admitted patients with SHCN.

For primary dentition, Group A showed higher prevalence of extractions of molars and incisors, lower prevalence of composite fillings, lower prevalence of pulp therapy and lower prevalence of crown restorations, when compared to healthy children, with statistically significant differences. This may be due to the presence of higher caries activity coupled with more un-restorable primary teeth in the children with SHCN when compared to healthy children. These results are in agreement with most of the previous studies ${ }^{12-20,22,24}$, where the use of extraction as a radical treatment approach in children with SHCN when compared to healthy children was observed.

There was no statistically significant difference between amalgam filling treatments in the two Groups. This finding may be attributed to the fact that most of the restorable teeth in both Groups were suffering of extensive decay where restoration with crowns was the preferred treatment choice.

In case of Group A, the Study notes a higher prevalence of glass ionomer fillings used for treating restorable primary molars with initial lesions. This particular note may reflect the personal preference of the operators to use a material has the potential of releasing fluoride in children with anticipated deficient oral hygiene status ${ }^{25}$. 
The Study deduces that the number of treatments using crowns exceeds that of treatments via pulp therapy. This observation reflects firstly the clinical success of using crowns in restoring both primary incisors and molars; and secondly, in maintaining the integrity of these teeth for a longer period of time regardless their oral hygiene status.

Higher prevalence of extractions, fillings, crowns and oral prophylaxis for the permanent teeth in Group A are related to the higher mean age of this Group at the time of dental treatment under GA with a higher probability of the presence of more decayed permanent teeth.

Few cases were shown in this study to have fissure sealant treatments. This should drive the attention toward more care for applying preventive measures as a policy during treating children under GA.

This Study confirmed a different treatment approach under GA between Group A and Group B exists. More radical treatments, like extractions, were noted the suitable approach for children with SHCN. The Study also showed a lower prevalence of pulp therapy with a higher rate of permanent teeth restorations in Group A when compared to Group B. these findings compels the need for a well-established oral health education and that preventive strategies for children with SHCN are critically required. Education of parents/caregivers is mandatory to ensure appropriate and regular supervision of proper oral hygiene measures for the children with SHCN.

\section{CONCLUSIONS}

1- The use of radical treatment as extraction of teeth with extensive decay in children with SHCN is observed in this Study.

2- The use of crowns to protect the teeth even without pulp therapy is noticeable in the treatment pattern revealed in this study.

3- A special attention should be directed toward preventive procedures such as dental prophylaxis, fissure sealants and topical fluoride application.

4- Education of parents/caregivers is needed to ensure appropriate and regular supervision of proper oral hygiene measures for the children with SHCN.

\section{ACKNOWLEDGEMENT}

The author is immensely grateful to all the staff members and coworkers of the "Unit for Dental Treatment of Healthy Children and Children with SHCN", for their continual assistance in the provision of the dental treatment documented in this Study.

\section{REFERENCES}

1- American Academy of Pediatric Dentistry. Definition of special health care needs. Pediatr Dent. 2012; 34(special issue): 16 .

2- Albadri SS, Jarad FD, Lee GT, Mackie IC. The frequency of repeat general anesthesia for teeth extractions in children. Int J Paed Dent. 2006; 16:45-48.

3- Ibricevic H, Al-Jame Q, Honkala S. Pediatric dental procedures under general anesthesia at the Amiri Hospital in Kuwait. J Clin Pediatr Dent. 2001; 25:337-42.

4- Vargas Roman Mdel P, Rodriguez Bermudo S, MachucaPortillo G. Dental treatment under general anesthesia: a useful procedure in the third millennium? (1). Med Oral 2003; 8: 129-35.

5- Al-Eheideb AA, Herman NG. Outcomes of dental procedures performed on children under general anesthesia. J Clin Pediatr Dent. 2003; 27:181-3.

6- Eidelman E, Faibis S, Peretz B. A comparison of restorations for children with early childhood caries treated under general anesthesia or conscious sedation. Pediatr Dent. 2000; 22:33-37.

7- https://www.aapd.org/research/oral-health-policies-recommendations/special-health-care-needs/

8- Grytten J, Holst D, Dyrberg L, Faehn O. Some characteristics of patients given dental treatment under general anesthesia. Acta Odontol Scand 1989; 47:1 -5. 
9- Klein U, Nowak AJ. Characteristics of patients with autistic disorder (AD) presenting for dental treatment: a survey and chart review. Spec Care Dent. 1999; 19:200-207.

10- Machuca MC, Velez A, Machuca G, Tormos HL, Nieves E, Fernandez PB. Dental treatment under general anesthesia offered at Hospital Pedi'atrico Universitario de Puerto Rico during the years 1989-1994. P R Health Sci J. 1996; 15: 289-95.

11- Robertson S, Chaollai A Ni, Dyer TA (2012). What do we really know about UK pediatric dental general anesthetic services? Brit Dent J 212: 165-167.

12- Al-Ogayyel S, Al-Haj Ali S. Comparison of dental treatment performed under general anesthesia between healthy children and children with special health care needs in a hospital setting, Saudi Arabia. J Clin Exp Dent. 2018 Oct $1 ; 10(10): 963-969$.

13- Sari ME, Ozmen B, Koyuturk AE, Tokay U. A retrospective comparison of dental treatment under general anesthesia on children with and without mental disabilities. Niger J Clin Pract. 2014; 17:361-5.

14- Ahuja R, Jyoti B, Shewale V, Shetty S, Subudhi SK, Kaur M. Comparative Evaluation of Pediatric Patients with Mental Retardation undergoing Dental Treatment under General Anesthesia: A Retrospective Analysis. J Contemp Dent Pract. 2016; 17:675-8.

15- Tsai CL, Tsai YL, Lin YT, Lin YT. A retrospective study of dental treatment under general anesthesia of children with or without a chronic illness and/or a disability. Chang Gung Med J. 2006; 29:412-8.

16- Lee PY, Chou MY, Chen YL, Chen LP, Wang CJ, Huang WH. Comprehensive dental treatment under general anesthesia in healthy and disabled children. Chang Gung Med J. 2009; 32:636-42.

17- Tahmassebi, JF, Achol, LT and Fayle, SA (2014) Analysis of dental care of children receiving comprehensive care under general anesthesia at a teaching hospital in England. European Archives of Pediatric Dentistry, 15 (5). 353 360. ISSN 1818-6300

18- Zarina A, Normaizura M, Siti N. Utilization of dental general anesthesia for. Malaysian Journal of Medical Sciences, Vol. 15, No. 3, July 2008 (31-39).

19- Sreekanth K. \& Cynthia K.Y. Dental treatment under general anesthesia for specialneeds patients: analysis of the literature. Journal of Investigative and Clinical Dentistry. 2016; 7, 325-331.

20- Mitchell L, Murray JJ. Management of the handicapped and the anxious child: a retrospective study of dental treatment carried out under general anesthesia. J Paediatr Dent. 1985; 1: 9-14.

21- Stankova M, Bucek A, Dostalova T, Ginzelova K, Pacakova Z, Seydlova M. Patients with special needs within treatment under general anesthesia - meta-analysis . Prague Med Rep 2011; 112: 216-25.

22- Peretz B, Spierer A, Spierer S, Rakocz M. Dental treatment of patients with systemic diseases compared to patients with developmental disabilities under general anesthesia. Spec Care Dentist. 2012; 32: 21 -5.

23- Berkowitz RJ, Moss M, Billings RJ, Weinstein P. Clinical outcomes for nursing caries treated using general anesthesia. J Dent Child .1997; 64: 210-28.

24- Baygin O, Tuzuner T, Kusgoz A, Yahyaoglu G, Yilmaz N, Aksoy S. Effects of medical and mental status on treatment modalities in patients treated under general anesthesia at the KTU Faculty of Dentistry in Trabzon, Turkey: A comparative retrospective study. J Pak Med Assoc. 2017; 67: 305-7.

25- Sharat Chandra Pani. Comparison of high viscosity glass ionomer cement to composite restorations placed in primary teeth under general anesthesia. Pediatric Dental Journal. 2018; 28: 154-159. 